\title{
El cine como instrumento didáctico: análisis de tres documentales sobre la globalización
}

\author{
Francisco ENTRENA DURÁN \\ Universidad de Granada \\ fentrena@ugr.es
}

Recibido: $20 / 11 / 2012$

Aceptado: 23/01/2013

\begin{abstract}
Resumen dencias en su identificación de los problemas o procesos relacionados con dichos efectos.

Palabras clave: Globalización, cine documental, didáctica, alumnado.

\section{Cinema as a Teaching Tool: Analysis of Three Documentaries on Globalization}

El artículo estudia, desde el punto de vista de su utilidad para la didáctica del fenómeno de la globalización, los documentales 'Maquilápolis', 'Capitalismo: una historia de amor' e 'Inside Job'. Éstos han sido proyectados y debatidos, por el autor y sus alumnos/as de Sociología, con objeto de acrecentar su conocimiento y capacidades críticas ante dicho fenómeno. El análisis de tales documentales evidencia que, más allá de sus específicas aproximaciones a los efectos de la globalización, muestran ciertas coinci-

\begin{abstract}
The article examines, from the viewpoint of their usefulness for teaching globalization phenomenon, the documentaries 'Maquilápolis', 'Capitalism: a love story' and 'Inside Job'. These are watched and discussed, by the author and his students of Sociology, in order to further their knowledge and critical skills before globalization. The analysis of such documentaries reveals how, beyond their specific approaches to the effects of globalization, they show certain agreements in their identifications of problems or processes related to these effects.
\end{abstract}

Keywords: Globalization, documentary cinema, teaching, students.

\section{Referencia normalizada}

ENTRENA DURÁN, Francisco (2013): "El cine como instrumento didáctico: análisis de tres documentales sobre la globalización". Estudios sobre el Mensaje Periodístico. Vol. 19, Núm. especial marzo, págs.: 149-157. Madrid, Servicio de Publicaciones de la Universidad Complutense.

Sumario: 1. Introducción. 2. Metodología. 3. Desarrollo. 4. Conclusiones. 5. Referencias bibliográficas.

\section{Introducción}

La globalización se manifiesta actualmente como una situación, en la que las tecnologías disponibles (la televisión, la radio, la Internet, los medios de transporte y de locomoción, etc.) facilitan una intensa circulación, en todas las direcciones del planeta, de ideas, personas y mercancías (Castells, 1998; Beck, 2008). Este artículo pretende contribuir a la didáctica de estas circunstancias de interconexión global, algunos de cuyos efectos negativos son mostrados al alumnado de Sociología mediante la proyección de los documentales 'Maquilápolis', 'Capitalismo: una historia de amor' e 'Inside Job', los cuales se procura que el/la estudiante analice con ojo crítico (Martínez-Salanova, 2002). El objetivo de ello es estimular su concienciación y capacidad analítica, desarrollar sus facultades para crear a partir de los conocimientos que le son transmitidos y evitar que se limite a reproducirlos literalmente, tal y como observaron Williams y Colomb (1990) que solía suceder con bastantes de los/as ingresantes en la 
Universidad. Ante ello, un reto clave de la docencia universitaria es dotar a los/as estudiantes de actitudes y habilidades críticas adecuadas para evolucionar hacia nuevas formas de conocimiento con la potencialidad, no sólo de decir éste, sino sobre todo de transformarlo (Scardamalia y Bereiter, 1985).

Difícilmente pueden desarrollarse tales actitudes y habilidades críticas ante lo que no se conoce bien. Primero hay que entender claramente el problema o fenómeno que nos ocupa en cada momento, pues, cuando uno se encuentra en un terreno no familiar, el necesario ejercicio de comprensión de las circunstancias en las que está tiene que preceder a cualquier pretensión crítica (Chanock, 2001). En otras palabras, tenemos que identificar la naturaleza y las peculiaridades del contexto social donde nos movemos antes de poder plantearnos el trazado de caminos alternativos en ese contexto o allende de él. A este respecto, se busca aquí que los documentales analizados ayuden al alumnado en la comprensión de la globalización y sus implicaciones, así como en el subsiguiente desarrollo de sus actitudes y capacidades crítico-transformadoras ante ella. Al fin y al cabo, el cine es un medio didáctico muy útil para el logro de objetivos educativos, no sólo conceptuales, sino también actitudinales o reflexivos, lo cual resulta especialmente potenciado debido a que cualquier filme:

"presenta formas de ver, de concebir, de vivenciar el mundo en espacios y contextos particulares, ampliando la concepción que los espectadores tienen de sus vidas [a la vez que ofrece la posibilidad de] la confrontación de la imagen con las experiencias vividas de las personas y la construcción, re-configuración o consolidación de sentidos y significados que influyen en sus prácticas cotidianas. En la medida en que se identifican las imágenes de la pantalla con la vida real, se ponen en movimiento nuestras proyecciones-identificaciones propias de la vida real" (Morín, 1972: 108).

\section{Metodología}

Se hace aquí un análisis instrumental del cine (Zavala, 2010: 65 y ss.). Dicho análisis puede ser de naturaleza genética o ideológica. El primero se focaliza en las circunstancias personales y sociales en las que tiene lugar la creación y la producción cinematográfica, mientras que el ideológico, que es el que está más en consonancia con el método seguido en este trabajo, se orienta básicamente a analizar los contenidos y las tramas argumentales de las películas, consideradas éstas como narrativas que muestran diferentes procesos o fenómenos de naturaleza social, tales como la violencia, la injusticia, la corrupción o, en el presente caso, las consecuencias de los procesos de globalización. Tales consecuencias son mostradas al alumnado a través de los tres documentales estudiados en este trabajo, los cuales, más allá de su mayor o menor calidad artística, constituyen instrumentos didácticos útiles para la visualización o el reforzamiento de los mensajes y las narrativas sobre la globalización presentes en ellos.

Según el método de trabajo seguido, primero se procura que los/as alumnos/as que puedan vean anticipadamente en privado el documental a proyectar y traigan sintetizados sus contenidos, así como las ideas, comentarios o cuestiones, tanto para su presentación previa, como para el posterior debate. Esa presentación no tiene por qué ser hecha por el profesor, sino que, bajo la dirección y asesoramiento de éste, puede cualquier alumno/a responsabilizarse de ella. En todo caso se procura que ese/a alumno/a 
no limite su disertación a lo que se conoce como la ficha técnica del documental (título, dirección, producción, guión, fotografía, protagonistas, país, año, género, duración, clasificación, compañías, distribución, etc.), sino que, sobre todo, haga referencia a las temáticas y los conceptos del programa docente que se manifiestan en el mismo.

Luego, tras las proyecciones en clase de los documentales, además de pedir a los/as alumnos/as breves trabajos escritos individuales sobre lo visto, se organizan una serie de debates conjuntos entre el profesor y ellos/as (uno a continuación de cada visionado y otro general tras la proyección de los tres documentales) en torno a la utilidad de la actividad realizada para entender la globalización, sus impactos en nuestras vidas y las incertidumbres y los retos que ello nos genera. Un objetivo clave de dichos debates es examinar a fondo las tramas argumentales de los documentales vistos, así como sus particulares encadenamientos de imágenes y las narrativas construidas de este modo. La finalidad de ello es que el alumnado llegue a valorar y analizar a fondo el filme visto, que sea capaz de descomponerlo, de sintetizarlo (o de recomponerlo), de interpretarlo en sí mismo, en tanto que relato que contiene una peculiar estructura narrativa acerca de la realidad social en él tratada y constituye, por lo tanto, una forma específica de construir imaginariamente (mediante su secuencia de imágenes) y discursivamente (a través de sus diálogos) las lógicas socioeconómicas, los valores y los símbolos culturales que subyacen a dicha realidad y/o la articulan.

El propósito central de esta estrategia metodológica de anticipación, presentación, visionado y análisis de los documentales cinematográficos es fortalecer la comprensión y la capacidad de crítica del alumnado acerca de la realidad social reflejada en ellos. Se trata de fomentar en él un aprendizaje reflexivo/reactivo que no se limite a la mera recepción de contenidos y conceptos, sino que también le incite a implicarse en el necesario cambio de los valores y las reglas de juego y, consecuentemente, en la lucha contra las consecuencias negativas de la globalización.

En consonancia con esta metodología, las consideraciones analíticas sobre los documentales seleccionados que se hacen seguidamente son producto, no sólo de las habilidades teórico-interpretativas de quien esto escribe, sino que también es justo reconocer lo que esas habilidades hayan podido mejorar con la lectura de los escritos del alumnado y la toma en cuenta de sus reflexiones acerca de dichos documentales.

\section{Desarrollo}

Tras sintetizar sus temáticas específicas, se estudian aquí conjuntamente los tres documentales seleccionados. En primer lugar, 'Maquilápolis', producido por Vicky Funari y Sergio de la Torre, trata de las maquiladoras, unas industrias de ensamblaje de aparatos electrónicos con piezas importadas para luego ser, en su mayoría, exportados a los países desarrollados. Entre las marcas globales de dichas industrias están Sanyo, Sony, Panasonic, Tocabi, Deltech, Sohnen, Kelmex o Nichiba. Las dos protagonistas principales del documental, Carmen Durán y Lourdes Luján, organizadas en el Colectivo Chilpancingo, trabajan por articular un movimiento social de protesta para enfrentarse a los intereses y/o a las maquiladoras causantes de las duras condiciones ambientales, laborales y vitales que padecen. Pero, 'Maquilápolis' nos resalta también la valía de sus mujeres protagonistas y dignifica su exasperantemente reiterativo 
trabajo taylorista en la maquila, representándonos muy imaginativamente el ritmo y la maestría de las manos femeninas, cuyas habilidades para el repetitivo trabajo en cadena son escenificadas con una seductora belleza artística. Su excelente dramatización y la alta expresividad de los lenguajes corporales de sus protagonistas, así como de sus imágenes, hacen de 'Maquilápolis' una valiosa herramienta pedagógica. Particularmente, tales imágenes escenifican, con excepcional atractivo artístico y capacidad para seducir y concienciar al espectador, la explotación y las desigualdades de género que sufren las mujeres, quienes han de compaginar, en unas penosas y sobrecargadas temporalidades cotidianas, sus roles como madres y como trabajadoras nocturnas de la maquila.

En segundo lugar, 'Capitalismo: una historia de amor', dirigido por Michael Moore, es muy adecuado para la didáctica de consecuencias de la globalización, tales como la deslocalización y la desindustrialización, las crisis socioeconómicas, el paso del capitalismo fordista de producción industrial masiva al capitalismo financiero básicamente especulativo. Los problemas de especulación urbanística, desolación urbana y social, desahucios, aumento de las desigualdades, deterioro del Estado de Bienestar, desempleo, pobreza y exclusión social que ello suele generar son abordados por Moore desde una militancia encaminada a concienciarnos y a movilizarnos.

Por último, 'Inside Job', un documental conocido también como Trabajo confidencial y como Dinero Sucio, ha sido dirigido por Charles Ferguson. Comienza con la crisis económico-financiera de Islandia (2008-2009), un modelo de sociedad de bienestar, sin apenas delincuencia y con muy buen nivel de vida, que sufrió dicha crisis tras las desregulaciones financieras, el boom inmobiliario y las privatizaciones de sus bancos. Ello tuvo gravísimas consecuencias para la economía y para un entorno caracterizado por un encomiable grado de equilibrio ecológico. Luego, se nos habla de la caída de Lehman Brothers, en Septiembre de 2008, del subsiguiente desplome de la generalidad de los mercados financieros y de cómo esto causó una crisis financiera y una recesión globales, cuyas devastadoras consecuencias todavía se hacen sentir (muy especialmente, en España), habiendo llevado a la pobreza a millones de personas del planeta y a que muchos jóvenes tengan unas expectativas de futuro peor que las de sus padres. Esta situación no ha ocurrido por accidente, sino como efecto de esa serie de desregulaciones financieras que comenzaron con las políticas, supuestamente 'liberalizadoras' de la economía, puestas en marcha en los años ochenta por los gobiernos de Reagan y Thatcher. Como resultado de ello, las finanzas acabaron funcionado fuera de control y favoreciendo la propagación de una especulación económica desligada de la producción real, uno de cuyos efectos más negativos fue la exacerbación de los apetitos de ganancias a corto plazo en el sector financiero, lo que llevó a muchos a realizar operaciones bastante arriesgadas. Operaciones hechas en la confianza, por parte de sus artífices y/o responsables, de que, al fin y al cabo, ellos no perderían nada, pues la factura de sus acciones la acabarían pagando otros. Realmente, así ha sucedido, de tal modo que es especialmente inquietante que los mismos causantes del desastre financiero, al percatarse de las consecuencias de sus actos, suscribieron seguros contra sus previsibles pérdidas, con lo que, no sólo lograron frecuentemente eludir las responsabilidades penales, sino incluso salir beneficiados. 
Pero, más allá de sus particulares aproximaciones a los efectos de la globalización, es posible encontrar coincidencias en los problemas o procesos que los documentales seleccionados refieren en relación con dichos efectos. Seguidamente se identifican algunos de los más significativos de esos problemas o procesos, así como se exponen los matices o puntos de vista con los que son abordados en tales documentales.

A) Industrialización.- Mientras que en 'Inside Job' y, sobre todo, en 'Capitalismo: una historia de amor' se enfatiza el papel que cumple la industrialización en la creación de empleo y de bienestar (se añora el pasado fordista de casi pleno empleo), en 'Maquilápolis' se resalta que la industrialización conlleva deterioro y contaminación ambiental, explotación laboral y enfermedades relacionadas con ello.

B) Deslocalizaciones industriales hacia otros lugares con costes laborales y ambientales menores.- 'Inside Job', se centra en analizar la economía financiera-especulativa, por lo que éste problema ni siquiera lo menciona. En cambio, en 'Capitalismo: una historia de amor' se nos muestran imágenes de desolación asociadas a las deslocalizaciones y cierres industriales y al desempleo y la pobreza que ello genera. También 'Maquilápolis' alude brevemente a las deslocalizaciones de las maquiladoras hacia Asia en busca de mano de obra más dócil y barata, paralelamente al aumento de las capacidades organizativas, movilizadoras y reivindicativas de sus protagonistas.

C) Desterritorialización.- Este fenómeno, que es consustancial a la globalización, se refiere a como con ella se extienden y afianzan intereses y procesos de toma de decisiones de alcance global, los cuales se gestan, cada vez en mayor medida, fuera de los territorios locales concretos a los que afectan. Ello ocurre en un contexto de desregulación económico-financiera, en el que prácticamente existe libertad para el flujo planetario de las mercancías y, sobre todo, de los capitales (Sassen, 2007). Es precisamente esta facilidad para el flujo de capitales y mercancías la que posibilita esa economía especulativo-financiera global de cuyos negativos efectos se ocupan 'Inside Job' y 'Capitalismo: una historia de amor'. También la producción para un mercado global, por parte de las fábricas donde trabajan las protagonistas de 'Maquilápolis', es una muestra de desterritorialización de la producción.

D) La inmoralidad del capitalismo.- El documental de Moore alude directamente a dicha inmoralidad. Como dice el propio Moore, "no creo que Jesús haya venido a la tierra para hacer sonar la campana de la bolsa de Nueva York y, sin embargo, desde el principio los ricos se lo han apropiado". En consonancia con ello este cineasta se declara católico y nos dice que lo es porque le interesa el compromiso prioritario de Jesús con los pobres. Jesús se negaría a formar parte de lo que conlleva el capitalismo, afirma un obispo entrevistado por Moore, quien considera que el "capitalismo es un mal y el mal no se puede regular, hay que erradicarlo y reemplazarlo por algo que sea bueno para todos, y ese algo se llama democracia".

Los otros dos documentales también consideran inmoral al capitalismo. Primero, en 'Inside Job' se habla de los derroches, la prostitución de lujo o la drogadicción que eran habituales entre los altos ejecutivos de las empresas causantes del desastre financiero, algunas de las cuales blanquearon dinero, estafaron a clientes y maquillaron sus libros contables una y otra vez. Este es el caso del Banco Riggs, que lavó dinero del dictador chileno Augusto Pinochet, de Credit Suisse, que ayudó a canalizar fon- 
dos hacia el programa nuclear de Irán o de Citibank, que contribuyó a desviar 100 millones de dólares del narcotráfico mexicano. Respecto a 'Maquilápolis', si bien no alude directamente a la inmoralidad de las circunstancias fruto de la globalización capitalista que nos presenta, nos muestra esas circunstancias con toda su crudeza quedando claro lo moralmente rechazables que son sus negativos efectos sobre las vidas cotidianas y las condiciones socio-laborales y ambientales.

E) Privatización de beneficios y socialización de pérdidas.- Tanto en 'Capitalismo: una historia de amor' como en 'Inside Job' vemos como, tras el gran fiasco causado por la desregulada economía financiero-especulativa, los grandes potentados económico-financieros recurren al gobierno para que con dinero público les permita recuperarse de las pérdidas. Con ello se favorece la conversión de su deuda privada en deuda pública o, también, lo que se ha conceptuado como una socialización de las pérdidas por los mismos que con tanto empeño habían abogado por la privatización de las ganancias.

F) Globalización como interconexión global.- En mayor o menor grado, los problemas o los procesos socioeconómicos acontecidos en cualquier lugar del planeta afectan a los de otras partes de él o son afectados por éstos. Los tres documentales analizados aquí coinciden en tratar esta interconexión global de una u otra forma. Primero, los productos de las maquiladoras de Tijuana (México) que aparecen en 'Maquilápolis' se exportan a todo el mundo, dependiendo la evolución del empleo en esa zona del grado de deslocalización de dichas maquiladoras hacia países de Asia. Respecto a 'Inside Job', vemos como la caída de Lehman Brothers, uno de los centros neurálgicos del sistema financiero global, acarreó la crisis en cadena de otra serie de grandes entidades financieras del mundo originando un colapso de dicho sistema. Finalmente, el documental de Moore muestra la interconexión global cuando relaciona el éxito y la crisis industrial en Norteamérica, respectivamente, con las imágenes de destrucción económico-productiva de la Europa de posguerra y con la industrialización japonesa y europea.

\section{Conclusiones}

Cada uno de los documentales estudiados encara de modo diferente los efectos de la globalización. Así, mientras que 'Maquilápolis' escenifica y visualiza muy bien sus negativos efectos ambientales y socio-laborales, 'Capitalismo: una historia de amor' sobresale por la intencionalidad preponderantemente movilizadora de su director/productor Michael Moore contra los desahucios, los despidos derivados de los cierres de empresas, las consecuencias de las deslocalizaciones industriales y otros desmanes del capitalismo financiero planetario. Finalmente, 'Inside Job' adopta un enfoque marcadamente analítico que logra explicar, detallada y claramente, al público no conocedor a fondo de los entresijos económico-financieros, los desregularizados e imprudentes procedimientos de actuación que siguieron las empresas dedicadas a la especulación financiera; en particular, el mercado de derivados y de préstamos de alto riesgo conocido como los 'subprime' o hipotecas basura.

Por lo tanto, mientras que los dos primeros documentales tienen un marcado propósito sensibilizador, concienciador y/o movilizador, la finalidad prioritaria de 'In- 
side Job' es la de explicarnos el origen de la crisis económico-financiera de manera entendible y precisa, valiéndose para ello de lo que dicen los numerosos expertos, políticos y personajes del mundo de las finanzas a los que entrevista. Particularmente, analiza muy bien el origen de la burbuja inmobiliaria que precedió a la crisis financiera en los Estados Unidos, lo cual, dada la difícil situación socioeconómica que estamos ahora sufriendo en España, es muy oportuno para aportar a los/as estudiantes bases para la comprensión de las causas de lo que nos está pasando.

Desde otro punto de vista, los tres documentales analizados manifiestan un más o menos acentuado compromiso ético con la necesidad de trabajar por un mundo más solidario y justo que el que se asienta sobre el modelo de globalización neoliberal predominante en la actualidad, a la vez que suscitan en el espectador la predisposición a adoptar ese compromiso. Sin embargo, en cada uno de ellos, en consonancia con su específica estructura argumental y su particular lógica narrativa, se produce esto de manera distinta y, por consiguiente, cada uno de ellos tiene una utilidad didáctica diferente. En primer lugar, en 'Maquilápolis', los propios personajes que sufren el impacto de la globalización en sus vidas cotidianas son implicados como actores en su trama dramático-argumental. Esto contribuye fuertemente a familiarizar e identificar empáticamente al espectador con la realidad de los sueños y las frustraciones de dichas vidas, las cuales se nos hacen especialmente atrayentes por diferentes virtudes humanas de sus protagonistas mayoritariamente femeninas, tales como su ejemplaridad como madres o su cotidiano esfuerzo por aumentar su formación y grado de concienciación social para así avanzar en lo personal y, sobre todo, para cambiar a mejor las $\operatorname{cosas}^{1}$. Con este fin, las mujeres de 'Maquilápolis' establecen relaciones interactivas entre ellas, encaminadas a fortalecer su conciencia solidaria y a reivindicar colectivamente la solución a sus problemas. En segundo lugar, 'Capitalismo: una historia de amor', a la vez que se opone a esa economía financiero-especulativa altamente desvinculada de la producción real de bienes tangibles, alienta la búsqueda de un mundo más justo y equitativo, para cuya consecución Moore propone la alternativa de las empresas cooperativas, al mismo tiempo que no duda en incitar a la protesta reivindicativa. En cambio, en 'Inside Job', la concienciación frente a la injusticia es un resultado lógico del análisis y la explicación detallada de sus causas y consecuencias que en él se hace. Análisis que logra que el espectador medio entienda los nefastos efectos de las decisiones desreguladoras y los procesos desencadenantes de la crisis financiera.

Por último, los relatos o imaginarios sobre la realidad socioeconómica de la globalización, contenidos en las tramas argumentales y en las lógicas narrativas de los documentales estudiados, contribuyen a facilitar o incentivar el papel de los espectadores (en tanto que actores sociales) en la construcción, deconstrucción y reconstrucción de

1 Me ha suscitado estas argumentaciones Beatriz Peña cuando en otro contexto dice que, "si se contempla la calidad de estas series, uno de sus puntos fuertes es la apuesta por que el espectador se familiarice con cada uno de los personajes en el tiempo y las relaciones interactivas entre ellos. Son personajes atrayentes por sus virtudes o simpatía o debilidad humana, pero de alguna manera los hacen asequibles y simpáticos a la audiencia" (2009: 7). 
esa realidad, respecto a la que les proporcionan paradigmas y sentidos interpretativos, así como patrones para actuar en o ante ella. Aquí estriba precisamente la utilidad didáctica de tales documentales. Una utilidad que no sólo proviene del hecho de que mediante la proyección de los mismos pueden ser visualizados mejor los efectos de la globalización por el alumnado, sino que también es debida a que éste, tras esa proyección y el subsiguiente debate, suele encontrar en ello referentes éticos que lo sensibilizan e incitan a implicarse en la transformación social hacia un mundo más justo, así como a comprometerse con el desarrollo de los valores humanos, los cuales, junto con las personas, han de estar por encima de la economía (Sesé, 2001: web).

\section{Referencias bibliográficas}

BECK; Ulrich (2008): ¿Qué es la globalización?: Falacias del globalismo, respuestas a la globalización. Barcelona, Paidós.

CASTELLS; Manuel (1998): La era de la información: economía, sociedad y cultura. Madrid, Alianza Editorial.

CHANOCK, Kate (2001): "From Mystery to Mastery", en TRIVETT, Neil: Changing Identities: Refereed proceedings from the 2001 Language and Academic Skills conference. New South Wales, University of Wollongong: http://learning.uow.edu.au/LAS2001/selected/chanock.pdf [fecha de consulta: 8 de noviembre de 2012].

MARTÍNEZ-SALANOVA; Enrique (2002): Aprender con el cine, aprender de pelicula: una visión didáctica para aprender e investigar con el cine. Huelva, Grupo Comunicar Ediciones.

MORIN; Edgar (1972): El Cine o el Hombre Imaginario. Barcelona, Seix Barral.

PEÑA, Beatriz (2009): "Las series de televisión de máxima audiencia". Revista de Comunicación Vivat Academia, ${ }^{\circ}$ 104: http://www.ucm.es/info/vivataca/numeros/n104/Num104/DATOSS104.htm. [fecha de consulta: 29 de agosto de 2012].

SASSEN; Saskia (2007): Una sociología de la globalización. Buenos Aires, Katz Editores.

SCARDAMALIA, Marlene y BEREITER, Carl (1985): "Development of dialectical processes in composition", en OLSON, David R., TORRANCE, Nancy y HILDYARD, Angela: Literacy: Language and Learning. Cambridge, Cambridge University Press, pp. 307-329.

SESÉ, José María (2001): "Las humanidades en la Universidad del tercer milenio. Lección inaugural de curso" (Universidad de Piura -Perú-): http://ebookbrowse.com/las-humanidades-en-la-universidad-del-tercer-milenio-jose-mariasese-piura-2001-doc-d38746711. [fecha de consulta: 30 de agosto de 2012].

WILLIAMS, Joseph y COLOMB, Gregory G. (1990): “Two Metaphors for Learning", en FULWILER, Toby y YOUNG, Art: Programs that Work: work: models and methods for writing across the curriculum. Portsmouth, New Hampshire, Boynton/Cook Publishers, pp. 97-111. 
ZAVALA, Lauro (2010): "El análisis cinematográfico y su diversidad metodológica", Revista Casa del Tiempo, vol. 3, época 4, no 30: http://www.difusioncultural.uam .mx/casadeltiempo/30_iv_abr_2010/index.php. [fecha de consulta: 28 de agosto de 2012].

\section{Francisco ENTRENA DURÁN}

Universidad de Granada. Departamento de Sociología

fentrena@ugr.es

Catedrático de Universidad 